\title{
FATTY ACIDS AS BIOCOMPOUNDS: THEIR ROLE IN HUMAN METABOLISM, HEALTH AND DISEASE - A REVIEW. PART 1: CLASSIFICATION, DIETARY SOURCES AND BIOLOGICAL FUNCTIONS
}

\author{
Eva Tvrzicka*, Lefkothea-Stella Kremmyda, Barbora Stankova, Ales Zak \\ $4^{\text {th }}$ Department of Internal Medicine, ${ }^{\text {st }}$ Faculty of Medicine, Charles University in Prague, Czech Republic \\ E-mail: eva.tvrzicka@vfn.cz
}

Received: March 8, 2011; Accepted with revision: June 13, 2011

Key words: Fatty acids/Human metabolism/Saturated/Monounsaturated/Polyunsaturated/Dietary sources/Lipid classes

Background. Fatty acids are substantial components of lipids and cell membranes in the form of phospholipids. This review consists of two parts. The present part aims at describing fatty acid classification, dietary sources and biological functions. The second part will focus on fatty acid physiological roles and applications in human health and disease.

Results. In humans, not all fatty acids can be produced endogenously due to the absence of certain desaturases. Thus, specific fatty acids termed essential (linoleic, alpha-linolenic) need to be taken from the diet. Other fatty acids whose synthesis depends on essential fatty acid intake include eicosapentaenoic acid and docosahexaenoic acid, found in oily fish. Dietary sources of saturated fatty acids are animal products (butter, lard) and tropical plant oils (coconut, palm), whereas sources of unsaturated fatty acids are vegetable oils (such as olive, sunflower, and soybean oils) and marine products (algae and fish oils). Saturated fatty acids have been related to adverse health effects, whereas unsaturated fatty acids, especially monounsaturated and n-3 polyunsaturated, are thought to be protective. In addition, trans fatty acids have been shown to have negative effects on health, whereas conjugated fatty acids might be beneficial. Lastly, fatty acids are the main components of lipid classes (triacylglycerols, phospholipids, cholesteryl esters, non-esterified fatty acids).

Conclusion. Fatty acids are important biocompounds which take part in complex metabolic pathways, thus having major biological roles. They are obtained from various dietary sources which determine the type of fat consumed and consequently health outcome.

\section{INTRODUCTION}

Dietary modifications that have occurred over time include changes in the type of fat consumed toward increased consumption of saturated animal fat in particular, and lower intake of unsaturated fat (plant and marine sources) (ref., ${ }^{1,2}$. This change in the composition of diet may have a great effect on the fatty acid composition of human tissues and affect metabolism and health ${ }^{3}$.

Fatty acids (FA) play multiple roles in humans and other organisms. Most importantly, FA are substantial part of lipids, one of the three major components of biological matter (along with proteins and carbohydrates) $\left(\right.$ ref. $\left.^{4}\right)$. Fatty acids are also important energy substrates comprising around $30 \%$ of total energy intake for humans. They can be stored in excess amounts in adipose tissue, especially when increased dietary intake of fat and energy occurs resulting in obesity.

Fatty acids are either saturated or unsaturated carboxylic acids with carbon chains varying between 2 and 36 carbon atoms. Polyunsaturated FA (PUFA) are characterized by pentadiene configuration of double bonds. Most FA have an even number of carbon atoms, as they are synthesized from two-carbon units. Specifically, fatty acids are synthesized ad hoc in the cytoplasm from twocarbon precursors, with the aid of acyl carrier protein, NADPH and acetyl-CoA-carboxylase. Their degradation by $\beta$-oxidation in mitochondria is accompanied by energy release.

Fatty acid composition is species as well as tissue specific. In animal and plant tissues, the most abundant FA are those with 16 and 18 carbon atoms, i.e. palmitic, stearic, oleic and linoleic. Fatty acids in mammalian organisms reach a chain-length of 12-24 carbon atoms, with 0-6 double bonds. However, fatty acids with chain lengths shorter than 14 and longer than 22 carbon atoms are present only in minor concentrations. Approximately half of the FA in plants and animals are unsaturated and contain 1-6 double bonds.

Fatty acids can be desaturated endogenously up to the $\Delta 9$ position due to lack of certain enzymes in humans ( $\Delta 12$ - and $\Delta 15$-desaturases). For this reason linoleic (LA; 18:2n-6) and $\alpha$-linolenic (ALA; 18:3n-3) acids must be taken from the diet and are termed essential. Further elongation and desaturation of these fatty acids to produce long-chain (LC) PUFA, including eicosapentaenoic acid (EPA; 20:5n-3), docosahexaenoic acid (DHA; 22:6n-3) and arachidonic acid (AA; 20:4n-6), is possible but not very efficient in humans. Thus, these fatty acids may be characterized as conditionally essential depending on essential fatty acid availability. Recommendations for minimum dietary intake of EPA plus DHA vary between $250-450 \mathrm{mg} /$ day, especially for pregnant women and those 
of reproductive age $e^{5,6}$. Rich sources of these LC n-3 PUFA are fish oils and the flesh of oily fish.

From a chemical point of view, lipids are esters of fatty acids with organic alcohols - cholesterol, glycerol and sphingosine. Lipids circulate in the blood stream in the form of lipoproteins, which are composed of cholesteryl esters, triacylglycerols, and phospholipids. Non-esterified fatty acids are bound to plasma albumin. Fatty acids in the form of phospholipids (mainly phosphatidylcholine, phosphatidylethanolamine, and sphingomyelin) form the back bone of all cell membranes and are essential for their fluidity and functionality.

The present review on the role of FA as biocompounds consists of two parts. The first part aims at presenting and discussing FA nomenclature, physicochemical properties, biosynthesis, classification according to saturation, dietary sources, and biological function, as well as the structure and role of lipid classes. The second part of this review (to be published in the next volume of Biomedical Papers) will focus on FA physiological roles and applications in human health and disease as growth and development, cardiovascular health, cancer, and immune system disorders.

\section{FATTY ACID NOMENCLATURE}

Fatty acids are carboxylic acids with a typical $\mathrm{RCOOH}$ structure, containing a methyl end, a hydrocarbon chain (R) and a carboxylic terminus. Fatty acids have both a systematic and a common name (e.g. octadecanoic and stearic). They are also often expressed as a schematic formula (shorthand notation) as in $\mathrm{CN}$ :p n-x, where $\mathrm{CN}$ (carbon number) represents total number of carbon atoms, $\mathrm{p}$ - number of double bonds, $\mathrm{x}$ - position of the first double bond from the methyl terminus (n) (ref. ${ }^{7}$ ). For example, the shorthand notation for linoleic acid (9,12-octadecadienoic acid) is $18: 2 \mathrm{n}-6$ since it has 18 carbon atoms, and 2 double bonds of which the first one is on the sixth carbon atom counted from the methyl end. A different way of expressing the position of the first double bond is counting from the carboxylic terminus and this is indicated as the $\Delta$ position. An example would be that the position of the first double bond in $\alpha$-linolenic acid (18:3n-3) counting from the carboxylic group is $\Delta 9$. The structural formulas as well as types of shorthand notations are shown in (Fig. 1). Important fatty acids ${ }^{8}$ involved in metabolic pathways are summarized in (Table 1).

\section{PHYSICOCHEMICAL PROPERTIES OF FATTY ACIDS}

The melting point of fatty acids increases with the length of the hydrocarbon chain (i.e. $\mathrm{CN}$ ), and it decreases with the number of double bonds. This property is also reflected in compounds where FA represent an important component (phospholipids, triacylglycerols), as well as in higher organized structures (plasma membranes, lipoproteins). Under physiological conditions, double bonds preferably have a cis-configuration, which causes a $30^{\circ}$ deflection (curve) of the carbon chain. This results in the cis-unsaturated chain occupying greater space, decreasing van der Waals interactions and thus the melting point ${ }^{9}$.

Moreover, the degree of unsaturation (number of double bonds in cis-configuration) significantly influences cell membrane microviscosity and thickness, and consequently also the function of associated proteins (enzymes, cell receptors, membrane transporters and ion channels).

The water solubility of FA decreases as the chain lengthens. In diluted solutions, FA are present as monomers. However, in higher concentrations they form micelles. The concentration, above which FA associate into micelles, is called the critical micellar concentration. In

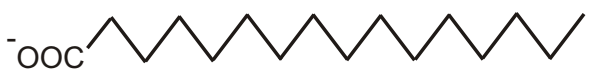

palmitic acid (16:0)
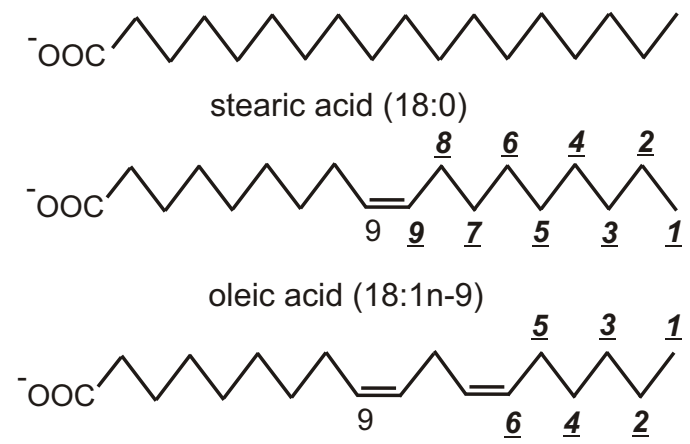

linoleic acid $(18: 2 n-6)$

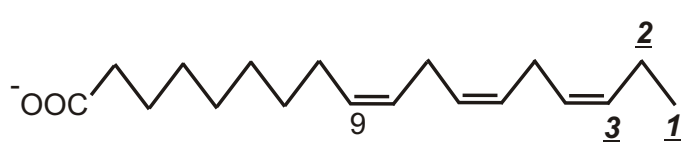

a-linolenic acid (18:3n-3)
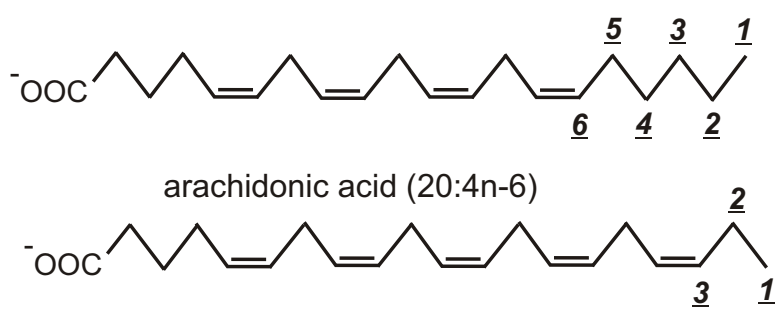

eicosapentaenoic acid (20:5n-3)

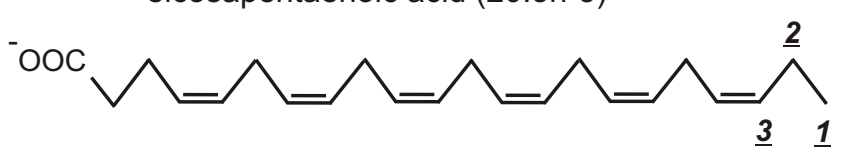

docosahexaenoic acid (22:6n-3)

Fig. 1. Structural formulas and types of shorthand notations of fatty acids. 
Fatty acids as biocompounds: their role in human metabolism, health and disease - a review.

Part 1: classification, dietary sources and biological functions

Table 1. Fatty acids relevant in metabolic pathways in vertebrates.

\begin{tabular}{|c|c|c|c|c|c|}
\hline Notation & $\begin{array}{c}\text { Systematic name } \\
\text { by IUPAC }\end{array}$ & Trivial name & Abbreviation $^{c}$ & $\begin{array}{l}\text { Molecular } \\
\text { mass }\end{array}$ & $\begin{array}{l}\text { Melting point } \\
\left({ }^{\circ} \mathrm{C}\right)\end{array}$ \\
\hline $4: 0$ & tetranoic & butyric & & 88.11 & $-7.9-5.1$ \\
\hline $6: 0$ & hexanoic & caproic & & 116.16 & $-3.4-3.9$ \\
\hline $8: 0$ & octanoic & caprylic & & 144.22 & $16.3-16.7$ \\
\hline $10: 0$ & decanoic & capric & & 172.27 & $31.2-31.6$ \\
\hline $12: 0$ & dodecanoic & lauric & & 200.32 & $44.0-44.2$ \\
\hline $14: 0$ & tetradecanoic & myristic & MA & 228.38 & $53.9-54.4$ \\
\hline $14: 1 n-5$ & cis-9-tetradecenoic & myristoleic & MOA & 226.37 & \\
\hline $16: 0$ & hexadecanoic & palmitic & PA & 256.43 & $62.5-63.1$ \\
\hline $16: 1 n-9$ & cis-7-hexadecenoic & & & 254.411 & \\
\hline $16: 1 \mathrm{n}-7$ & cis-9-hexadecenoic & palmitoleic & POA & 254.411 & -0.5 \\
\hline $18: 0$ & octadecanoic & stearic & SA & 284.48 & $67-69.6$ \\
\hline $18: 1 n-9$ & cis-9-octadecenoic & oleic & $\mathrm{OA}$ & 282.47 & 16.3 \\
\hline $18: 1 n-9$ & trans-9-octadecenoic & elaidic & & 282.47 & $44-46$ \\
\hline $18: 1 n-7$ & cis-11-octadecenoic & vaccenic & VA & 282.47 & $43-44$ \\
\hline $18: 2 \mathrm{n}-6$ & cis, cis-9,12-octadecadienoic & linoleic & LA & 280.46 & $-5(-9)$ \\
\hline $18: 3 n-6$ & all cis-6,9,12-octadecatrienoic & $\gamma$-linolenic & GLA & 278.44 & \\
\hline $18: 3 n-3$ & all cis-9,12,15-octadecatrienoic & $\alpha$-linolenic & ALA & 278.44 & $-11(-17)$ \\
\hline $18: 4 n-3$ & all cis-6,9,12,15-octadecatetraenoic & stearidonic & & 276.417 & \\
\hline 20:0 & eicosanoic & arachidic & AA & 312.54 & $\begin{array}{c}75.3-75.4 \\
(74-76) \\
\end{array}$ \\
\hline $20: 1 n-11$ & cis-9-eicosenoic & gondoleic & & 310.518 & \\
\hline $20: 1 n-9$ & cis-11-eicosenoic & gondoic & & 310.518 & \\
\hline $20: 2 n-6$ & cis,cis-11,14-eicosadienoic & & & 308.502 & \\
\hline $20: 3 n-9$ & all cis-5,8,11-eicosatrienoic & Mead & & 306.487 & \\
\hline $20: 3 n-6$ & all cis-8,11,14-eicosatrienoic & $\begin{array}{l}\text { dihomo- } \gamma- \\
\text { linolenic }\end{array}$ & DHGLA & 306.487 & \\
\hline $20: 4 n-6$ & all cis-5,8,11,14-eicosatetraenoic & arachidonic & $\mathrm{AA}$ & 304.471 & -49.5 \\
\hline $20: 5 n-3$ & all cis-5,8,11,14,17-eicosapentaenoic & timnodonic & EPA & 302.455 & -54 \\
\hline 22:0 & docosanoic & behenic & & 340.60 & $\begin{array}{c}79.9-80.0 \\
(74-78)\end{array}$ \\
\hline $22: 1 n-11$ & cis-11-docosenoic & cetoleic & & 338.58 & \\
\hline $22: 1 n-9$ & cis-13-docosenoic & erucic & & 338.58 & 33.8 \\
\hline $22: 2 n-6$ & cis,cis-13,16-docosadienoic acid & & & 336.556 & \\
\hline $22: 3 n-6$ & all cis 10,13,16-docosatrienoic acid & & & 334.540 & \\
\hline $22: 4 n-6$ & all cis-7,10,13,16-docosatetraenoic & adrenic & & 332.524 & \\
\hline $22: 5 n-3$ & all cis-7,10,13,16,19-docosapentaenoic & & DPA-3 & 330.509 & \\
\hline $22: 5 n-6$ & all cis-4,7,10,13,16-docosapentaenoic & & DPA-6 & 330.509 & \\
\hline $22: 6 n-3$ & all cis-4,7,10,13,16,19-docosahexaenoic & clupadonic & DHA & 328.493 & $-44.7,-44.5$ \\
\hline $24: 0$ & tetracosanoic & lignoceric & & 368.641 & $75-83$ \\
\hline $24: 1 n-9$ & cis-15-tetracosenoic & nervonic & NA & 366.625 & $42-43$ \\
\hline $26: 0$ & hexacosanoic & cerotic & & 396.7 & $87-88$ \\
\hline $28: 0$ & octacosanoic & montanic & & 424.7 & 90.9 \\
\hline $30: 0$ & triacontanoic & melissic & & 452.8 & $93-94$ \\
\hline
\end{tabular}

micelles, the carboxyl sides are oriented into the water phase, while hydrophobic (aliphatic) parts are packed within the centre ${ }^{10}$. Fatty acids esterified in phospholipids can form liposomes which are widely used in medicine $^{11}$ as well as in other fields (cosmetics). Micelles and liposomes are schematically shown in (Fig. 2) (based on Nelson \& Cox, 2005) (ref. ${ }^{12}$ ).

\section{BIOSYNTHESIS OF FATTY ACIDS}

Fatty acids are synthesized from two or three carbon precursors, with the aid of acyl carrier protein, NADPH and acetyl-CoA-carboxylase ${ }^{4}$. The elongation is via malonyl-CoA in the microsomal system and acetyl$\mathrm{CoA}$ in the mitochondrial system. Their degradation by 


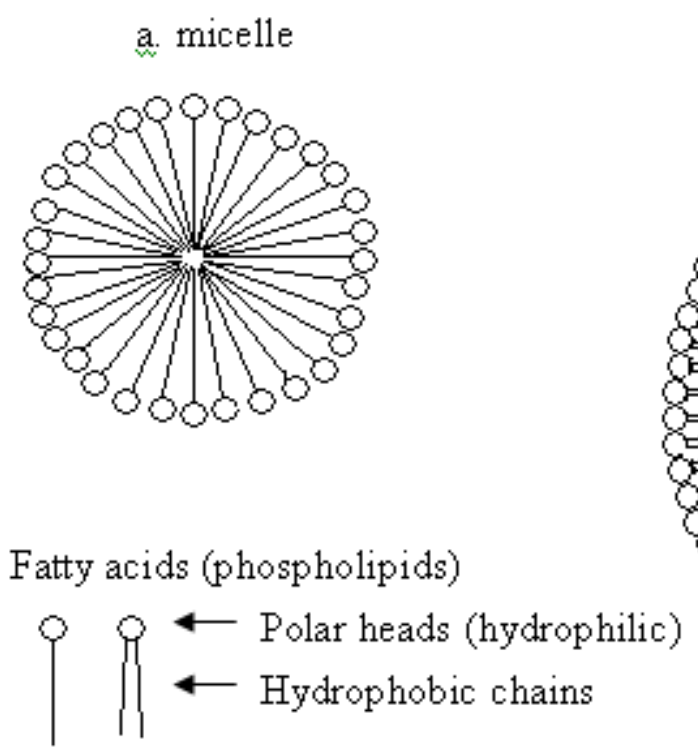

a. micelle

Fatty acids (phospholipids)

$99 \longleftarrow$ Polar heads (hydrophilic)

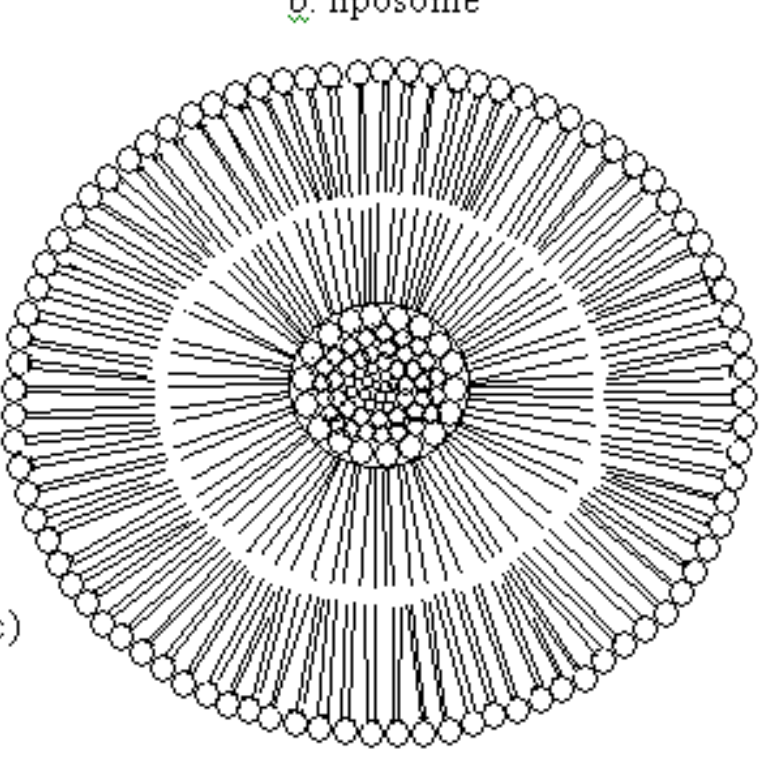

Fig. 2. Schematic structure of micelles (a) and liposomes (b). In micelles, the hydrophobic chains of fatty acids are turned inwardly towards the core of the sphere, whereas polar heads are on the outer layer. There is virtually no water in the interior. Liposomes are three-dimensional hollow vesicles enclosing an aqueous cavity. They are formed when the two-dimensional bilayer folds on itself.

$\beta$-oxidation in mitochondria is accompanied by energyrelease. Approximately 60 FA have been identified in blood plasma and tissues. However, only some of them are important from a biological point of view.

The composition of FA in individual species is predominately determined genetically but can be modified by diet. Mammals, including humans, are able to synthesize saturated FA, preferably with straight chain and even number of carbon atoms. Monounsaturated FA (MFA) are formed by introducing a double bond in position $\Delta 9$ counting from the carboxyl carbon. The reaction is catalyzed by the enzyme $\Delta 9$-desaturase ${ }^{4}$. Polyunsaturated FA contain 2-6 double bonds in pentadiene configuration (i.e. methylene interruption of the double bonds).

Typically, desaturation of stearic acid (18:0) results in oleic acid (18:1 n-9) and that of palmitic acid (16:0) in palmitoleic acid (16:1 n-7). As shown schematically in (Fig. 3), MFA of the n-9 with 20-24 carbon atoms are elongation products of oleic acid, whereas those of the $\mathrm{n}-11$ family are desaturation and elongation products of arachidic acid (20:0). Further desaturation $(\Delta 6, \Delta 5)$ and elongation of oleic acid produces Mead acid (20:3 n-9), which is produced in humans only when dietary intake of essential FA (EFA) is not sufficient ${ }^{13,14}$. Essential FA include LA for n-6 family, and ALA for n-3 family. Essential FA are PUFA which have their first double bond located on the third ( $\mathrm{n}-3$ family) or the sixth ( $\mathrm{n}-6$ family) carbon atom counting from the methyl terminus of the hydrocarbon chain. Essential FA cannot be synthesized in humans due to lack of $\Delta 12$ - and $\Delta 15$-desaturases which are present only in plants and marine algae $\mathrm{e}^{4}$, and thus, the human organism is completely dependent on their dietary intake. Further elongation and desaturation of these fatty acids to produce LC PUFA, including EPA, DHA and AA, is performed but not that efficiently in humans. Thus, these fatty acids may be characterized as conditionally essential depending on essential fatty acid availability. The metabolic pathways of EFA are schematically shown in (Fig. 4). It should be noted that fatty acids in individual metabolic pathways differ in their affinity to enzymes and their ability to inhibit desaturases (the FA affinity ratio is $\mathrm{n}-3: \mathrm{n}-6: \mathrm{n}-9 \sim 10: 3: 1)$.

\section{FATTY ACID CLASSIFICATION, DIETARY SOURCES AND BIOLOGICAL FUNCTIONS}

Total fat, as well as the type of fat, determine the effect of their consumption on health ${ }^{15,16}$. Fatty acids can be divided into several groups with respect to their structure, physiological role and biological effects. In the following paragraphs fatty acids are classified according to their structure as saturated and unsaturated.

\section{Saturated fatty acids}

Saturated FA (SFA) do not contain any double bonds and can be divided into subgroups according to their chain length:

Short chain (saturated) fatty acids (SCFA), include acetic (2:0), propionic (3:0), and butyric (4:0) acids, which are formed during fibre fermentation in the proximal colon. They are quickly absorbed, and acetic and partially also propionic acids are resorbed by portal circulation, transported to the liver and transformed into glucose (propionic acid) and FA (acetic acid). This process can cover $10-20 \%$ of resting energy expenditure (REE) 
Fatty acids as biocompounds: their role in human metabolism, health and disease - a review.

Part 1: classification, dietary sources and biological functions

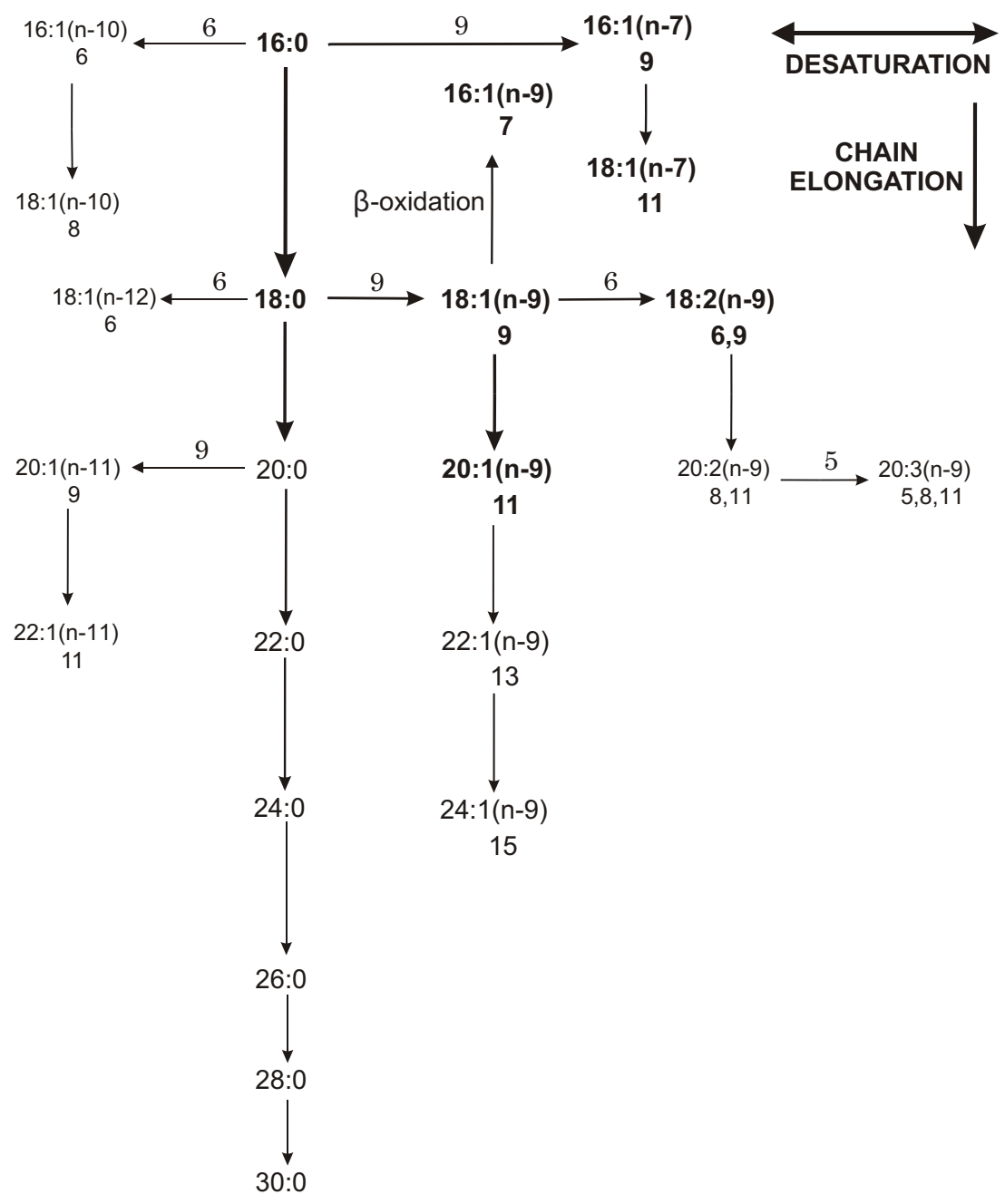

Fig. 3. Elongation and desaturation of endogenous fatty acids.
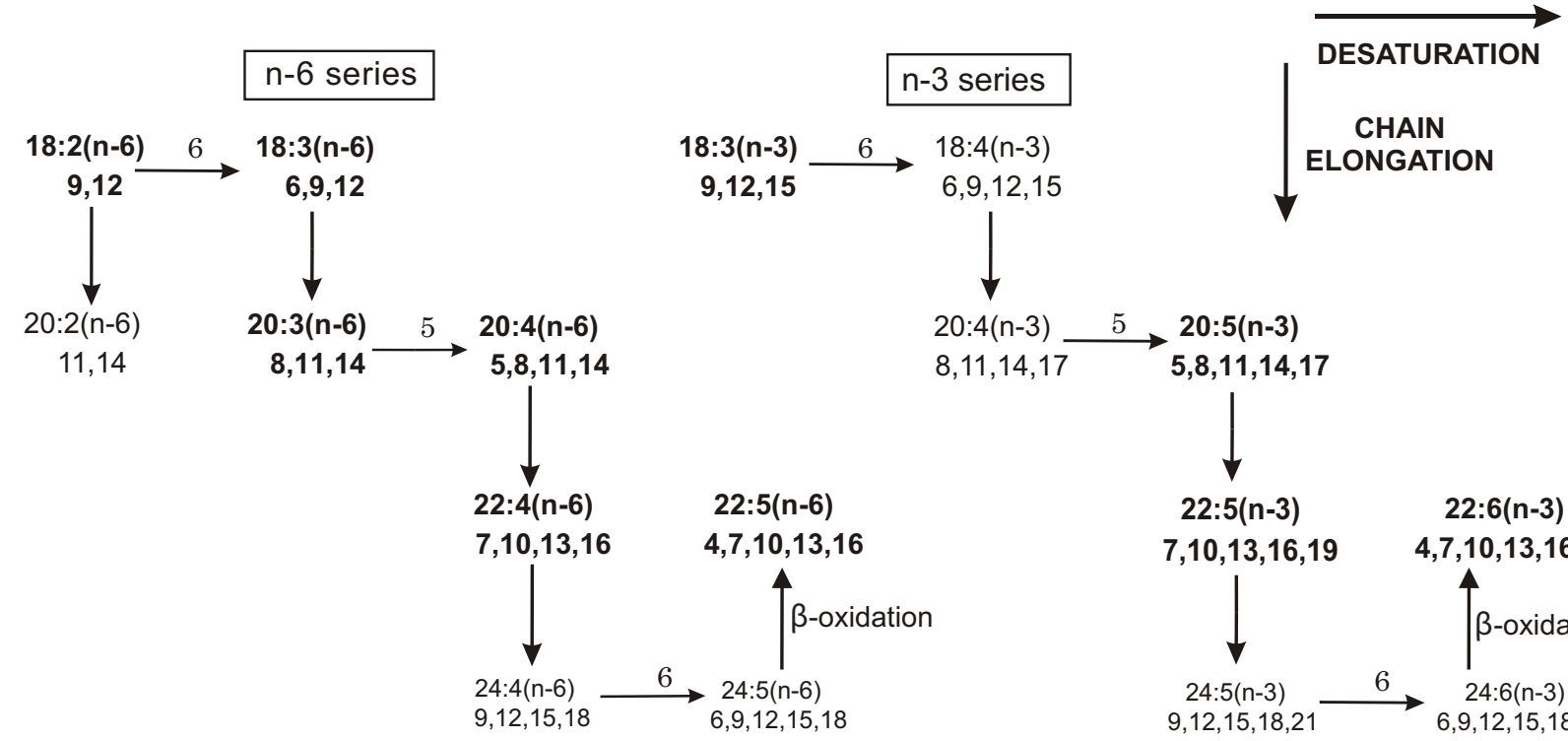

$20: 5(n-3)$
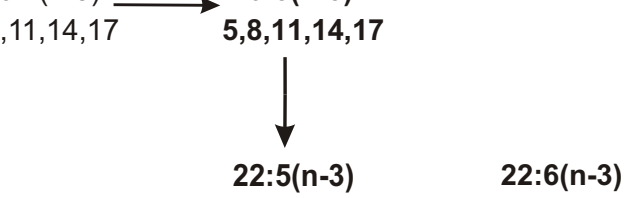

$7,10,13,16,19 \quad 4,7,10,13,16,19$

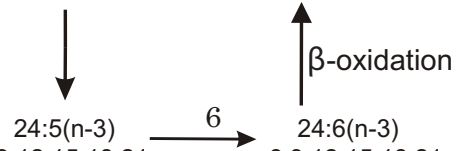

Fig. 4. Elongation and desaturation of essential fatty acids of the $n-3$ and $n-6$ families. In human tissues these pathways are rather slow. 
of the human body. Importantly, butyric and partially also propionic acids are used in metabolism, proliferation and restoration (cell replication) of colonocytes.

Other functions of SFA in the colon also include stimulation of:

1) water, sodium, chloride and bicarbonate absorption

2) blood flow through mucous membrane of the colon

3) colonocyte proliferation

4) mucus production

5) limited reproduction of saprophytic bacteria and putrefication due to decreased acidity ${ }^{17}$.

Medium chain (saturated) fatty acids (MCFA) include caproic (6:0), caprylic (8:0), and capric (10:0) acids, which are resorbed directly and transported by the portal vein. Their intramitochondrial transfer does not need the presence of carnitine or carnitine palmitoyl transferases. Fat emulsions containing medium chain triacylglycerols (MCT) are used as nutritional support in enteral nutrition. These have shorter biological half-time and higher stability to lipoperoxidation. These emulsions also inhibit decrease of REE during caloric restriction. Thus they are recommended in some cases of restrictive dietary regimen for obese individuals ${ }^{18}$.

Long chain (saturated) fatty acids (LCFA) include lauric (12:0), myristic (14:0), palmitic (16:0), and stearic (18:0) acids have significant atherogenic and thrombogenic potential. These FA, originating mainly in coconut oil (Cocos/Nucifera), palm kernel oil (Elaeis guineensis), cocoa butter (Theobroma cacao), shea butter (Butyrospermum parkii, synonymous to Vitellaria paradoxa) (ref. ${ }^{19,20}$ ) and illipe butter (Bassia latifolia), represent $80-90 \%$ of total SFA from food intake. The last three sources, which are substantial components of chocolate products, also contain approximately $35 \%$ of oleic acid. Animal sources of LCFA are butter, lard and beef tallow ${ }^{21}$. A variation of canola oil producing plant has been cultivated to have a high content of stearic acid (up to 40\%) which is advantageous when margarines are produced. Table 2 shows the percentage of individual FA for fats and oils rich in SFA (ref. ${ }^{22}$ ).

Consumption of saturated LCFA increases levels of cholesterol, namely that of low density lipoprotein (LDL)cholesterol, which is connected with increased coronary heart disease (CHD) mortality ${ }^{23}$. The effect of saturated LCFA in increasing LDL-cholesterol decreases in the direction 12:0 - 14:0 - 16:0 (ref. $^{24,25}$ ). On the other hand, the high density lipoprotein (HDL)-cholesterol lowering effect of saturated LCFA decreases in the direction 14:0-12:0-16:0 (ref. ${ }^{26,27}$ ). In contrast, some studies have shown that stearic acid (18:0) decreases LDL- and increases HDL-cholesterol, which may suggest that it has

Table 2. Average percentage of individual fatty acids in oils and fats rich in saturated fatty acids.

\begin{tabular}{|c|c|c|c|c|c|c|c|c|}
\hline $\begin{array}{c}\text { Fatty } \\
\text { acid }\end{array}$ & Coconut & $\begin{array}{c}\text { Palm } \\
\text { kernel }\end{array}$ & $\begin{array}{c}\text { Palm } \\
\text { fruit pulp }\end{array}$ & Cocoa & Shea & Illipe & Lard & Butter \\
\hline $4: 0$ & - & - & - & - & - & - & - & 3.2 \\
\hline $6: 0$ & 0.5 & & - & - & - & - & - & 2.0 \\
\hline $8: 0$ & 7.8 & 3.3 & - & - & - & - & - & 1.2 \\
\hline $10: 0$ & 6.7 & 3.4 & - & - & - & - & - & 2.5 \\
\hline $12: 0$ & 47.5 & 48.2 & 0.1 & - & - & - & - & 2.6 \\
\hline $14: 0$ & 18.1 & 16.2 & 1.0 & - & - & - & - & 7.4 \\
\hline $16: 0$ & 8.8 & 8.4 & 44.3 & 25.0 & 4.3 & 17.0 & 26.5 & 21.7 \\
\hline $16: 1 n-7$ & - & - & - & - & - & - & 3.0 & - \\
\hline $18: 0$ & 2.6 & 2.5 & 4.6 & 38.0 & 38.1 & 45.0 & 13.0 & 10.0 \\
\hline $18: 1 n-9$ & 6.2 & 15.3 & 38.7 & 32.0 & 48.6 & 35.0 & 45.5 & 17.0 \\
\hline $18: 2 n-6$ & 1.6 & 2.3 & 10.5 & 3.0 & 7.1 & 1.0 & 8 & 2.2 \\
\hline $18: 3 n-6$ & - & - & 0.3 & - & 0.3 & - & - & - \\
\hline $18: 3 n-3$ & - & - & - & - & - & - & - & 0.3 \\
\hline $20: 0$ & - & - & - & - & 1.2 & - & - & 0.1 \\
\hline SFA & 92.0 & 82.0 & 50.0 & 63.0 & 43.6 & 62.0 & 40.5 & 50.7 \\
\hline MFA & 6.2 & 15.3 & 38.7 & 32.0 & 48.6 & 35.0 & 48.5 & 17.0 \\
\hline PUFA & 1.6 & 2.3 & 10.8 & 3.0 & 7.4 & 1.0 & 8.0 & 2.2 \\
\hline n-6 & - & - & - & - & - & - & - & 0.3 \\
\hline PUFA & 99.8 & 99.6 & 99.5 & 98.0 & 99.6 & 98.0 & 97.0 & 70.2 \\
\hline n-3 & & & & & & & & \\
\hline
\end{tabular}

SFA, saturated fatty acids; MFA, monounsaturated fatty acids; PUFA, polyunsaturated fatty acids

Source: U.S. Department of Agriculture, Agricultural Research Service. 2010. USDA National Nutrient Database for Standard Reference 22 Note: Percentages may not add up too $100 \%$ due to some FA traces not listed; where \% FA varied average values were used. 
antiatherogenic properties ${ }^{28,29}$. Also, it has been shown that stearic acid did not increase postprandial inflamma$\operatorname{tion}^{30}$. However, it has been suggested that stearic acid has the highest prothrombotic potential compared to other saturated LCFA, although this is under debate ${ }^{31}$. The significance of the increased content of saturated fatty acids in membrane lipid rafts is not yet quite clear ${ }^{32}$.

The atherogenic and thrombogenic potentials of FA can be expressed as atherogenic (AI) and thrombogenic (TI) indices ${ }^{33}$ :

$\mathrm{AI}=\left[4 \times 14: 0+16: 0 \times\left[\mathrm{n}-6 \mathrm{PUFA}+\mathrm{n}-3 \mathrm{PUFA}+\mathrm{MFA}^{-1}\right.\right.$; $\mathrm{TI}=[14: 0+16: 0+18: 0] \times[0.5 \times \mathrm{XMA}+0.5 \times \mathrm{x}-6 \mathrm{PUFA}+$ $3 \mathrm{x}$ n-3PUFA + n-3PUFA/ n-6PUFA $]^{-1}$

Very long chain (saturated) fatty acids (VLCFA) include arachidic (20:0), behenic (22:0), lignoceric (24:0), cerotic (26:0), montanic (28:0) and melissic (30:0) acids, which appear in significant concentrations in inherited metabolic diseases, e.g. Zellweger syndrome, X-linked adrenoleucodystrophy, Refsum's disease, Menkes' disea$\mathrm{se}^{34}$. Individuals suffering from these disorders may benefit from administration of n-3 PUFA.

\section{Unsaturated fatty acids}

\section{Monounsaturated fatty acids in cis configuration}

The cis term is used when the two hydrogens at the double bond are on the same side of the molecule as each other. This leads to a different orientation of the adjoining carbons across the double bond resulting in the molecule having a curved structure. Main representatives in this group are oleic $(18: 1 n-9 c)$, vaccenic ${ }^{35}(18: 1 n-7 c)$ and palmitoleic $(16: 1 n-7 c)$ acids. Other MFA synthesized en- dogenously - myristoleic $(14: 1 \mathrm{n}-5 c)$, gondoic $(20: 1 \mathrm{n}-9 c)$, erucic $(22: 1 n-9 c)$ and nervonic $(24: 1 n-9 c)$ acids - are present only in minor concentrations. Monounsaturated FA not synthesized de novo include gadoleic (20:1n-11c) and cetoleic (22:1n-11c) acids. Erucic acid, substantial part of noncultivated rapeseed oil (Brassica napus), is suggested to be cardiotoxic ${ }^{36}$. Experiments with erucic acid on rats have shown increased deposition of fat which is followed by the formation of myocardial lesions ${ }^{37,38}$. In human studies, dietary erucic acid was found to reduce the number of platelets and their membrane anisotropy ${ }^{39}$. These findings have initiated the cultivation of rapeseed oil with low content in erucic acid ${ }^{40}$.

Oleic acid $(18: 1 n-9 c)$ has antiatherogenic and antithrombotic properties as it has been shown to increase the HDL-/LDL-cholesterol ratio and decrease aggregation of thrombocytes. Incorporation of oleic acid into cholesteryl esters, triacylglycerols and phospholipids of lipoprotein particles increases their resistance to lipoperoxidation. Replacement of SFA by oleic acid (about 7\% of total energy intake (TEI), when total fat is maximum $30 \%$ of TEI) decreased concentration of triacylglycerols (TAG), LDL-cholesterol, and increased concentration of HDL-cholesterol, and regulated insulin sensitivity ${ }^{41}$. Olive oil has also been tested experimentally for its protective role in carcinogenesis ${ }^{42}$ and for its effect on the inflammatory response ${ }^{43}$. Olive oil (Olea europaea) is the main dietary source of oleic acid, however, it can also be found in canola oil (Canadian oil, low acid; cultivated Brassica campestris, Brassica napus, or Brassica juncea), hybrid safflower oil (Carthamus/Tinctorius), cultivated rapeseed oil (Brassica campestris), peanut oil (Arachis hypogaea), hazelnut oil (Corylus americana), sweet almond oil (Prunus

Table 3. Average percentage of individual fatty acids in oils rich in monounsaturated fatty acids.

\begin{tabular}{|c|c|c|c|c|c|c|c|c|}
\hline Fatty acid & Olive & $\begin{array}{c}\text { Rape } \\
\text { seed }^{*}\end{array}$ & $\begin{array}{c}\text { Rape } \\
\text { seed** }\end{array}$ & Canola & Almond & $\begin{array}{c}\text { Avocado } \\
\text { fruit pulp }\end{array}$ & Peanut & Hazelnut \\
\hline $12: 0$ & - & - & - & - & - & - & - & - \\
\hline $14: 0$ & - & - & - & - & - & - & - & - \\
\hline $16: 0$ & 11.0 & 2.7 & 4.0 & 4.0 & 7 & 10.6 & 9.5 & 5.2 \\
\hline $18: 0$ & 2.0 & 1.0 & 7.0 & 2.0 & 2 & 0.7 & 2.2 & 2 \\
\hline $18: 1 \mathrm{n}-9$ & 71.0 & 11 & 52.0 & 62.0 & 69 & 67.9 & 44.8 & 77.8 \\
\hline $18: 2 \mathrm{n}-6$ & 10.0 & 13.8 & 30.0 & 18.6 & 17 & 12.5 & 32 & 10.1 \\
\hline $18: 3 \mathrm{n}-6$ & - & - & - & - & - & - & - & - \\
\hline $18: 3 \mathrm{n}-3$ & 1.0 & 6.2 & 7.0 & 9.0 & - & 0.9 & - & - \\
\hline $20: 0$ & - & - & - & - & - & - & - & - \\
\hline SFA & 13.0 & 3.7 & 11.0 & 6.0 & 9.0 & 11.3 & 11.7 & 7.2 \\
\hline MFA & 71.0 & $52.0 *$ & 52.0 & 62.0 & 69 & 67.9 & 44.8 & 77.8 \\
\hline PUFA n-6 & 10.0 & 13.8 & 30.0 & 18.6 & 17 & 12.5 & 32 & 10.1 \\
\hline PUFA n-3 & 1.0 & 6.2 & 7.0 & 9.0 & - & 0.9 & - & - \\
\hline TOTAL & 95.0 & 75.7 & 100 & 95.6 & 95.0 & 92.6 & 88.5 & 95.1 \\
\hline
\end{tabular}

SFA, saturated fatty acids; MFA, monounsaturated fatty acids; PUFA, polyunsaturated fatty acids

Source: U.S. Department of Agriculture, Agricultural Research Service. 2010. USDA National Nutrient Database for Standard Reference ${ }^{22}$

Note: Percentages may not add up too $100 \%$ due to some FA traces not listed; where \% FA varied average values were used.

*Non-cultivated rape seed (mustard seed) oil (Brassica napus); contains about 41\% erucic acid (22:1n-9)

${ }^{* *}$ Cultivated rape seed oil (Brassica campestris) 
amygdalus dulcis) and avocado oil (Persea gratissima). Lower content of oleic acid (40-50\%) is found in palm oil (Elaeis guineensis), rice bran oil (Oryza sativa), corn oil (Zea mays) and sesame oil (Sesamum indicum). High content of hydroxyoctadecenoic acid, 18:1-OH, is found in castor oil (Ricinus communis). A number of oil producing plants have been genetically modified to have an increased content of oleic acid ${ }^{21}$. (Table 3 ) shows the percentage of individual FA for oils rich in MFA (ref. ${ }^{22}$ ).

\section{Monounsaturated fatty acids in trans configuration}

These are molecules that have one double bond in which the hydrogens are on the opposite side to one another resulting in a non-curved structure and thus, to physicochemical properties close to those of SFA, affecting cell membrane properties similarly to SFA. Main trans MFA are elaidic (18:1n-9t) and trans-vaccenic (18:1n-7t) acids. Trans FA are of exogenous origin. Their atherogenic effect ${ }^{44}$ is assumed to be greater than that of SFA. Also, trans MFA are twice as active in raising LDL-cholesterol and decreasing HDL-cholesterol than SFA. The different effects of trans FA and SFA on human metabolism are still being studied ${ }^{45,46}$. Main dietary sources of trans FA are hardenings or shortenings (such as margarines from hydrogenated plant oils using an improper catalyst) and butter (trans FA in milk originate from the gastrointestinal tract of ruminants). Hydrogenated fats are used mainly in pastry and the "fast-food" industry ${ }^{47}$. However, advances in technology used by the food processing industry have now reduced the production of trans fatty acids.

\section{Polyunsaturated fatty acids}

Polyunsaturated FA contain two or more double bonds in the molecule. In general, the more double bonds there in the fatty acid, the more prone they are to lipoperoxidation $^{48}$. Endogenous PUFA mostly belong to the n-9 family, synthesized in increased amounts when there is a lack of EFA (LA, ALA) $\left(\right.$ ref $\left.^{49}\right)$. These FA are termed essential because they cannot be synthesized de novo in humans and they are considered parental FA for the n-3 and n-6 PUFA families ${ }^{50}$. Essential FA exert beneficial antiatherogenic as well as antithrombotic effects. This is a result of their impact on lipoprotein concentration, membrane fluidity, function of membrane enzymes and receptors, modulation of eicosanoid production, regulation of blood pressure and metabolism of minerals ${ }^{51}$.

\section{n-3 Polyunsaturated fatty acids}

In the n-3 PUFA family the parent fatty acid is ALA. Its main metabolic products are EPA (timnodonic acid) and DHA (clupadonic acid), and to a lesser extent docosapentaenoic acid (DPA, 22:5n-3). These metabolites are termed LC n-3 PUFA. Dietary sources of ALA are seeds and leaves of some plants - soybeans (Glycine max), linseed (Linum usitatissimum), blackcurrant seeds (Ribes nigrum) and borage leaves (Borago officinalis), as well as their oils ${ }^{21}$. Its metabolites, EPA and DHA, can be taken from the diet through oily fish which are excellent sources containing approximately $2 \mathrm{~g}$ of EPA plus DHA per portion of fish (150 g). Among other fish, oily fish include sardines, mackerel, trout, salmon, fresh (not canned) tuna, and herring. Other sources of LC n-3 PUFA include fish oils, the liver of non-oily fish (such as cod and haddock), and the flesh of some white non-oily fish but in much lower amounts ${ }^{5}$. Conversion of ALA into 20-22 $\mathrm{CN}$ metabolites is much more effective in marine animals than in human species. Thus, EPA and DHA are in humans mostly of exogenous source ${ }^{52,53}$. The high content of DHA in nervous tissues and the retina is extremely important. Also, the unique properties of this FA play a role in the mechanism of signal transduction, probably by regulation of G-protein signaling ${ }^{54,55}$.

As ligands of peroxisome proliferator-activated receptor (PPAR- $\alpha$ ), n-3 PUFA have a number of pleiotropic effects on lipid and energy metabolism. They are thought to activate PPAR- $\alpha$ and decrease lipogenesis and very low density lipoprotein (VLDL) secretion ${ }^{56}$ by suppression of sterol response element binding protein (SREBP-1). Also, other potential effects of n-3 PUFA are to increase the activity of lipoprotein lipase, decrease concentrations of apo C-III and potentiate reverse cholesterol transport ${ }^{57,58}$. In the form of high concentration oil supplements, n-3 PUFA are thought to induce expression of uncoupling proteins (UCP) and increase density of mitochondria by $\beta$-oxidation of FA in muscles ${ }^{59-62}$. The immunomodulative properties of LC n-3 PUFA are connected with their ability to suppress the activation of T-lymphocytes ${ }^{63}$. This activation demands acylated proteins, localized in cell membrane lipid rafts, which leave the raft after increased exposure to (and thus content of) LC n-3 PUFA (ref. ${ }^{57,64}$ ).

\section{n-6 Polyunsaturated fatty acids}

In the n-6 PUFA family the parent fatty acid is LA. Its metabolic products are $\gamma$-linolenic (GLA; 18:3n-6), dihomo- $\gamma$-linolenic (DHGLA; 20:3n-6) and arachidonic acids, and in minor amounts also adrenic (22:4n-6) and docosapentaenoic (22:5n-6) acids. High concentrations of n-6 PUFA (>60\%) are found in soybean oil (Glycine soja), sunflower seed oil (Helianthus annuus), safflower oil (Carthamus tinctorius), evening primrose oil (Oenothera biennis), grape seed oil (Vitis vinifera), poppy seed oil (Populus nigra), borage seed oil (Borago officinalis), blackcurrant seed oil (Ribes nigrum), and lower concentrations (40-50\%) in wheat germ oil (Triticum vulgare), corn oil (Zea mays), walnut oil (Juglans regia), cottonseed oil (Gossypium) and sesame oil (Sesamum indicum), as well as the seeds of some of these plants ${ }^{21}$. (Table 4) shows the percentage of individual FA for oils rich in PUFA (ref. ${ }^{22}$ ).

Polyunsaturated FA of the n- 6 family are activators of PPAR $(\gamma>\alpha)$. Their metabolic effects include affecting cytokine production ${ }^{65}$, increased cholesterol synthesis, increased activity of LDL-receptors resulting from increased mRNA for LDL-receptors, increased activity of cholesterol 7 $\alpha$-hydroxylase (Cyp 7A1) and decreased conversion of VLDL to LDL (ref. ${ }^{66}$ ). Supplementation with n-6 PUFA leads to decreased total, LDL- and HDLcholesterol and increased sensitivity of LDL particles to lipoperoxidation. This effect is a result of the "upregulation" of LDL-receptors and the activity of Cyp 7A1. As ligands of PPAR- $\gamma$, n-6 PUFA increase insulin 
Table 4. Average percentage of individual fatty acids in oils rich in polyunsaturated fatty acids.

\begin{tabular}{|c|c|c|c|c|c|c|c|c|c|c|c|c|}
\hline $\begin{array}{c}\text { Fatty } \\
\text { acid }\end{array}$ & $\begin{array}{c}\text { Sunflower } \\
\text { seed }\end{array}$ & $\begin{array}{c}\text { Safflower } \\
\text { seed }\end{array}$ & $\begin{array}{c}\text { Pumpkin } \\
\text { seed }\end{array}$ & $\begin{array}{c}\text { Sesame } \\
\text { seed }\end{array}$ & Corn & $\begin{array}{c}\text { Soya } \\
\text { bean }\end{array}$ & Walnut & $\begin{array}{c}\text { Flaxseed } \\
\text { (linseed) }\end{array}$ & $\begin{array}{c}\text { Wheat } \\
\text { germ }\end{array}$ & $\begin{array}{c}\text { Hemp } \\
\text { seed }\end{array}$ & $\begin{array}{c}\text { Evening } \\
\text { primrose }\end{array}$ & $\begin{array}{c}\text { Borage } \\
\text { seed }\end{array}$ \\
\hline $12: 0$ & - & - & - & - & - & - & - & - & - & - & - & - \\
\hline $14: 0$ & - & - & - & - & - & - & - & - & - & - & - & - \\
\hline $16: 0$ & 7.0 & 7.0 & 9.0 & 9.0 & 11.0 & 11.0 & 7.0 & 5.0 & 16.0 & 6.0 & 6.0 & 10.3 \\
\hline $18: 0$ & 5.0 & 2.0 & & 4.0 & 2.0 & 4.0 & 2.0 & 4.0 & 0.5 & 2.0 & 2.0 & 3.6 \\
\hline $18: 1 \mathrm{n}-9$ & 19.0 & 13.0 & 33.5 & 42.0 & 28.0 & 22.5 & 22.2 & 21.0 & 14.6 & 12.0 & 7.3 & 16.0 \\
\hline $18: 2 \mathrm{n}-6$ & 68.0 & 78.0 & 50.5 & 45.0 & 58.0 & 50.0 & 52.0 & 16.0 & 55.0 & 58.0 & 74.0 & 37.0 \\
\hline $18: 3 \mathrm{n}-6$ & - & - & - & - & - & - & - & - & - & 2.0 & 9.0 & 23.3 \\
\hline $18: 3 \mathrm{n}-3$ & 1.0 & & 7.0 & & 1.0 & 7.0 & 10.0 & 53.0 & 6.9 & 20.0 & - & - \\
\hline 20:0 & - & - & - & - & - & - & - & - & - & - & - & - \\
\hline SFA & 12.0 & 9.0 & 9.0 & 13.0 & 13.0 & 15.0 & 9.0 & 9.0 & 16.5 & 8.0 & 8.0 & 13.9 \\
\hline MFA & 19.0 & 13.0 & 33.5 & 42.0 & 28.0 & 22.5 & 22.2 & 21.0 & 14.6 & 12.0 & 7.3 & 16.0 \\
\hline PUFA n-6 & 68.0 & 78.0 & 50.5 & 45.0 & 58.0 & 50.0 & 52.0 & 16.0 & 55.0 & 60.0 & 83.0 & 60.3 \\
\hline PUFA n-3 & 1.0 & - & 7.0 & - & 1.0 & 7.0 & 10.0 & 53.0 & 6.9 & 20.0 & - & - \\
\hline TOTAL & 100 & 100 & 100 & 100 & 100 & 94.5 & 93.2 & 99.0 & 93.0 & 100 & 98.3 & 90.2 \\
\hline
\end{tabular}

SFA, saturated fatty acids; MFA, monounsaturated fatty acids; PUFA, polyunsaturated fatty acids

Source: U.S. Department of Agriculture, Agricultural Research Service. 2010. USDA National Nutrient Database for Standard Reference ${ }^{22}$ Note: Percentages may not add up too $100 \%$ due to some FA traces not listed; where \% FA varied average values were used.

sensitivity, change the distribution of fat and the size of adipocytes $^{67,68}$. Importantly, AA is a major precursor of eicosanoids which are potent signalling molecules both inside and outside the cell ${ }^{69}$.

\section{Conjugated fatty acids}

As mentioned above, most PUFA are characterized by pentadiene configuration (i.e. methylene interruption) of the double bonds, with the exception of conjugated FA. Most abundant FA with a conjugated system of double bonds are isomers of LA (conjugated linoleic acid; CLA). These FA appear in red meat and dairy products; cows grazing pasture have a several times higher content of CLA in meat and milk fat than cows fed typical dairy diets. There are 28 possible isomers of CLA, which differ in the position (e.g. 7 and 9, 8 and 10,9 and 11, 10 and 12,11 and 13 - counting form the carboxyl group) and configuration (cis or trans) of double bonds. The type most commonly found in meat and dairy products is rumenic acid $(18: 2 \Delta 9 c, 11 t)$. Also, the isomer 18:2 $\Delta 10 t, 12 c$ has important metabolic effects ${ }^{70}$. Compared to previous generations, the current human population consumes less CLA in their diet preferring white to read meat and very low fat dairy products. Thus, CLA, containing equal amounts of $18: 2 \Delta 9 c, 11 t$ and $18: 2 \Delta 10 t, 12 c$ isomers, is frequently used as special dietary supplement.

The origin of conjugated FA is similar as that of trans FA. However, their biological effect is mostly positive $\mathrm{e}^{71,72}$. Conjugated FA are shown to have both in vitro and in vivo antioxidant properties (probably due to the production of FA with furan structures) and anticarcinogenic effects. Paradoxically, an anti-cancer effect of beef products was found in a study which included fried meat ${ }^{73,74}$. The isomer 18:2 $\Delta 10 t, 12 c$ inhibited fat accumulation in vivo, while the isomer 18:2 $\Delta 9 c, 11 t$ improved parameters of lipid metabolism affecting expression of SREBP-1c and liver $\mathrm{X}$ receptor $\alpha\left(\right.$ ref. $\left.^{75,76}\right)$. However, conflicting results have been obtained from animal and human studies ${ }^{77}$. Further studies focusing on the effects of different CLA isomers would help to resolve some of these issues.

\section{FATTY ACIDS: THE MAIN CONSTITUTIONAL COMPONENT OF LIPID CLASSES}

Simple lipids are esters of fatty acids with alcohols cholesterol, glycerol and sphingosine. With respect to the main component we differentiate the following individual lipid classes ${ }^{78}$ :

- fatty alcohol - wax esters

- cholesterol - cholesteryl esters

- glycerol - triacylglycerols, diacylglycerols, monoacylglycerols

- alkenylglycerol - ether lipids, glycerylether diesters

- phosphoglycerol - glycerophospholipids

- glycerylhexoside - glyceroglycolipids

- sphingosine - ceramides

- phosphosphingosine - sphingophospholipids

- glycosphingosine - glycosphingolipids

The structural formulae of these lipids are shown in (Fig. 5). The pathophysiological role of fatty acids is derived from that of individual lipids.

Lipids circulate in the bloodstream assembled along with proteins into large, soluble structures termed lipoproteins. Circulating lipids (in the form of lipoproteins) consist of cholesteryl esters (CE; $60-70 \%$ of total cholesterol) and TAG situated in the non-polar core of lipoproteins, and phospholipids (mainly phosphatidylcholine and sphingomyelin) and free cholesterol in the polar envelope. Non-esterified fatty acids (NEFA; product of lipolysis and source for lipid synthesis) are bound to plasma albumin ${ }^{79}$.

Cholesteryl esters represent the transport and storage form of cholesterol in the organism; at the temperature of 


\section{Structural formulas of lipid classes}
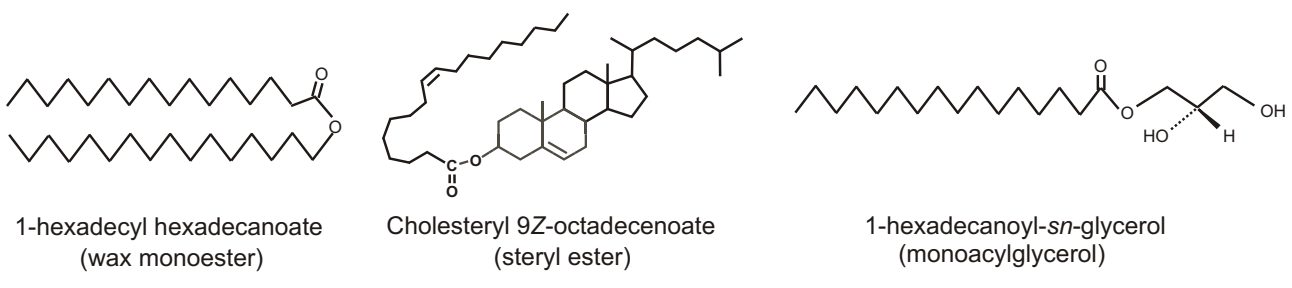

1-hexadecanoyl-sn-glycerol (monoacylglycerol)

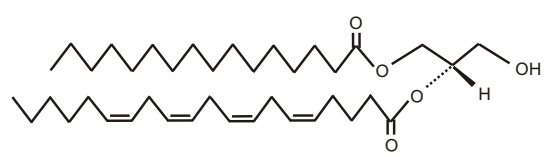

1-hexadecanoyl-2-(5Z,8Z, 11Z,14Z-icosatetraenoyl)-sn-glycerol (diacylglycerol)

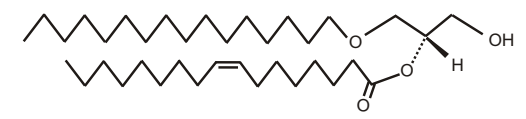

1-O-hexadecyl-2-(7Z-hexadecenoyl)-sn-glycerol (1-alkyl-2-acylglycerol)

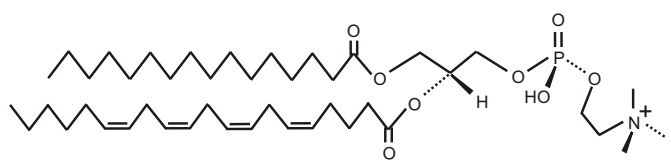

1-hexadecanoyl-2-(5Z,8Z,11Z,14Z-icosatetraenoyl)-sn-glycero-3-phosphocholine (phosphatidylcholine, glycerophosholipid)

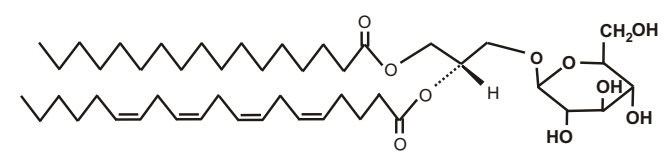

1-hexadecanoyl-2-(5Z,8Z,11Z,14Z-icosatetraenoyl)-3-O- -D-glucosyl-sn-glycerol (glycoglycerolipid)

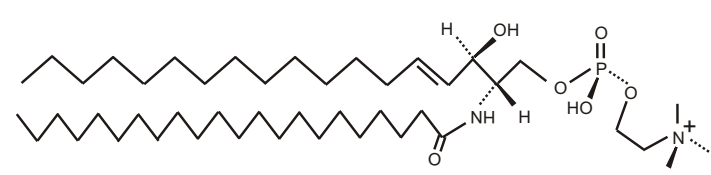

$\mathrm{N}$-(1-docosanoyl)-sphing-4-enine-1-phosphocholine (sphingomyeline, sphingophospholipid)

Fig. 5. Structural formulas of lipid classes.

the interior media they form liquid crystals. Cholesteryl esters in lipoproteins contain predominately linoleic acid (approx. 50\%), followed by oleic (18\%), palmitic (15\%) and arachidonic $(7 \%)$ acids ${ }^{80}$. Intracellularly stored cholesteryl esters contain predominately oleic and palmitoleic acids. In humans, cholesteryl esters are synthesized intravascularly through a reaction catalyzed by the enzyme lecithin:cholesterol acyltransferase (LCAT). This enzyme transfers LC PUFA from $\mathrm{C} 2$ carbon atom of lecithin to 3- $\beta-\mathrm{OH}$ group of cholesterol, thus forming cholesteryl ester and lysolecithin. Cholesteryl esters form a substantial

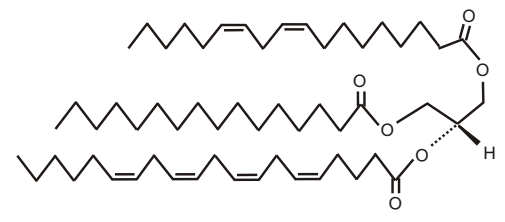

1-hexadecanoyl-2-(5Z,8Z,11Z,14Z-icosatetraenoyl)-3-(9Z,12Z-octadecadienoyl)-sn-glycerol (triacylglycerol)

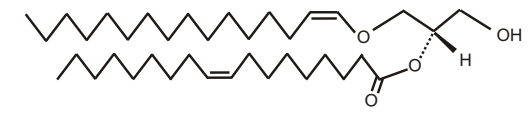

1-O-(1Z-hexadecenyl)-2-(9Z-octadecenoyl)-sn-glycerol (1-alkenyl-2-acylglycerol)

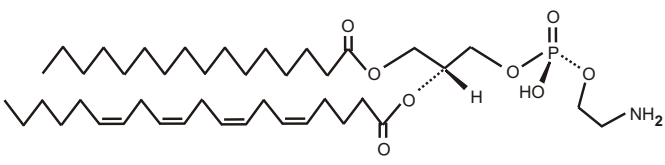

1-hexadecanoyl-2-(5Z,8Z,11Z,14Z-icosatetraenoyl)-sn-glycero-3-phosphoethanolamine (phosphatidylethanolamine, glycerophosholipid)

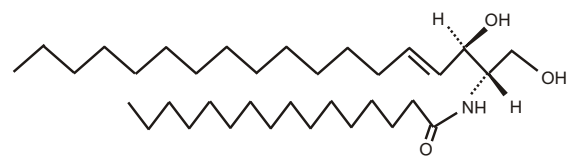

$\mathrm{N}$-(1-hexadecanoyl)-sphing-4-enine (ceramide)

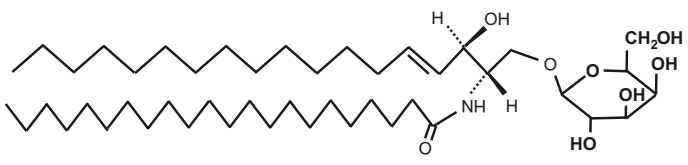

$\mathrm{N}$-(1-docosanoyl)-sphing-4-enine-3-O- -D-galactoside (galactocerebroside, glycosphingolipid)

part of the LDL and HDL core. Moreover they are a main component of lipid inclusion of macrophages and foam cells localized in atherosclerotic lesions.

Triacylglycerols are the main core components of VLDL and chylomicrons, as well as lipid inclusions of adipocytes. The most abundant FA in TAG is oleic acid (40\%) followed by palmitic (22\%) and linoleic (20\%) acids $^{81}$. A similar content of FA was also found in adipose tissue: oleic acid $-50 \%$, palmitic acid $-22 \%$ and linoleic acid - $12 \%$, since TAG are formed, partially, by FA re- 
leased from adipose tissue which are representative of its content.

Phospholipids (PL) are along with cholesterol the main lipids of the lipoprotein envelope and represent polar (hydrophilic) lipids. Molecules of PL are freely exchanged not only between individual lipoproteins, but also between the lipoprotein envelope and plasma membranes. This process is facilitated by specific transfer proteins. The composition and content of individual PL in the lipoprotein envelope is similar for the main lipoprotein classes, with the exception of chylomicrons. The most buoyant phospholipid class is phosphatidylcholine (PC, lecithin), whose content in plasma reaches $60-70 \%$, followed by sphingomyelin (SM, 10-20\%), lysolecithin (LPC, 3-5\%) and phosphatidylethanolamine (PE, 2-6\%). Minor phospholipids in plasma are phosphatidylserine (PS, 1-2\%) and phosphatidylinositol (PI, 1-2 \%). In plasma PC the dominating FA is palmitic acid (30\%), followed by linoleic $(25 \%)$, stearic $(14 \%)$, oleic $(11 \%)$ and arachidonic $(11 \%)$ acids $^{80}$. Plasma phospholipid FA content reflects in approximation that of cell membrane phospholipids and it thus may be characterized as the "functional" lipid pool.
The FA profile of the main plasma lipid classes of healthy individuals is shown in (Table 5) (ref. ${ }^{82}$ ).

Membrane lipids, which ensure fluidity and functionality, consist of PC, PE, SM and minor phospholipids (PS, PI, LPC and lysophosphatidylethanolamine-LPE). The fatty acid content in individual lipid classes influences substantially the membrane fluidity ${ }^{12}$. The two most abundant phospholipids in cell membranes are PC and PE, both predominately with palmitic acid and rich in PUFA. Usually PE has a higher content of PUFA. The head groups of phospholipids affect the membrane biochemical properties; some organelles may have much more PE than the cell membrane which is higher in SM. Moreover, the content of individual phospholipids in membranes and their fatty acid composition are species as well as tissue specific; liver cell membranes are high in PC, brain cell membranes are high in gangliosides, but bacterial membranes contain mostly PE.

Non-esterified FA are present in plasma under physiological conditions only in minor concentrations (0.5-1.0 $\mathrm{mmol} / \mathrm{l}$ ), their profile is similar to that of TAG and of adipose tissue, since they are released during TAG hydrolysis

Table 5. Fatty acid composition of cholesteryl esters, triacylglycerols, and phosphatidylcholine in plasma of healthy individuals.

\begin{tabular}{|c|r|r|r|}
\hline Fatty acid & PC & CE & TAG \\
\hline $14: 0$ & $0.28 \pm 0.13$ & $0.73 \pm 0.06$ & $1.97 \pm 1.00$ \\
\hline $16: 0$ & $29.10 \pm 2.50$ & $10.24 \pm 1.61$ & $25.44 \pm 3.76$ \\
\hline $16: 1 n-7$ & $0.56 \pm 0.23$ & $2.80 \pm 1.25$ & $3.49 \pm 1.10$ \\
\hline $18: 0$ & $13.80 \pm 1.33$ & $0.82 \pm 0.43$ & $3.60 \pm 1.16$ \\
\hline $18: 1 n-9$ & $10.16 \pm 1.78$ & $18.33 \pm 2.99$ & $39.15 \pm 4.66$ \\
\hline $18: 1 n-7$ & $1.78 \pm 0.45$ & $1.25 \pm 0.30$ & $2.78 \pm 0.59$ \\
\hline $18: 2 n-6$ & $24.24 \pm 3.22$ & $56.08 \pm 5.55$ & $17.68 \pm 4.58$ \\
\hline $18: 3 n-6$ & $0.09 \pm 0.06$ & $0.81 \pm 0.36$ & $0.34 \pm 0.19$ \\
\hline $18: 3 n-3$ & $0.24 \pm 0.10$ & $0.66 \pm 0.30$ & $1.19 \pm 0.52$ \\
\hline $20: 0$ & $0.06 \pm 0.03$ & $0.03 \pm 0.03$ & $0.07 \pm 0.05$ \\
\hline $20: 1 n-9$ & $0.15 \pm 0.04$ & $0.04 \pm 0.05$ & $0.45 \pm 0.03$ \\
\hline $20: 3 n-6$ & $2.94 \pm 0.66$ & $0.66 \pm 0.18$ & $0.31 \pm 0.13$ \\
\hline $20: 4 n-6$ & $10.63 \pm 1.94$ & $6.14 \pm 1.94$ & $1.25 \pm 0.46$ \\
\hline $20: 5 n-3$ & $0.91 \pm 0.42$ & $0.52 \pm 0.39$ & $0.23 \pm 0.14$ \\
\hline $22: 5 n-3$ & $0.92 \pm 0.20$ & $0.06 \pm 0.07$ & $0.34 \pm 0.12$ \\
\hline $22: 6 n-3$ & $3.21 \pm 0.82$ & $0.31 \pm 0.17$ & $0.55 \pm 0.37$ \\
\hline$\Sigma$ SFA & $43.06 \pm 3.34$ & $11.85 \pm 1.98$ & $31.24 \pm 4.72$ \\
\hline$\Sigma$ MFA & $12.74 \pm 2.13$ & $22.81 \pm 3.74$ & $46.14 \pm 4.90$ \\
\hline$\Sigma$ n-6 PUFA & $38.71 \pm 2.98$ & $63.79 \pm 5.18$ & $20.04 \pm 4.85$ \\
\hline$\Sigma$ n-3 PUFA & $5.27 \pm 1.20$ & $1.55 \pm 0.69$ & $2.31 \pm 0.84$ \\
\hline
\end{tabular}

$\Sigma$, sum; SFA, saturated fatty acids; MFA, monounsaturated fatty acids; PUFA, polyunsaturated fatty acids; PC, phosphatidylcholine; CE, cholesteryl esters; TAG, triacylglycerols

Note: Fatty acid composition is expressed as a molar percentage of total fatty acids in each lipid class.

Source: Zak et al. (2007) (ref. $\left.{ }^{82}\right)$ 
in adipocytes ${ }^{83}$. Non-esterified FA can be oxidized, reesterified, or metabolized (elongation and desaturation). During physical activity they are oxidized in muscles, whereas during resting periods they are oxidized in the liver and myocardium. Most NEFA are re-esterified in the liver to TAG and phospholipids. A limiting step for the mobilization of NEFA from adipose tissue to plasma is the activity of the responsible enzyme, hormone-sensitive lipase. An increased concentration of NEFA is toxic, affecting plasma membranes and resulting in arrhythmias, thrombogenesis etc. Together with increased glucose concentration, NEFA may accelerate the formation of the reactive oxygen and nitrogen substances (RONS), as well as initiation and development of endothelial dysfunction.

Lastly, some partial esters - monoacylglycerols (MG), diacylglycerols (DG), LPC and ceramides - are intermediate products of the synthesis or degradation of other simple as well as complex lipids. Their content in plasma is very low; some of them as second messengers (DG, inositoltriphosphate - $\mathrm{IP}_{3}$ ) can regulate a wide range of cell activities. The fatty acid composition in these minor lipids reflects that of parent lipid classes.

\section{CONCLUSION}

The first part of this review on FA as biocompounds presented their classification and dietary sources, as well as the complex metabolic pathways that FA are involved in. Fatty acids in the form of phospholipids are major components of cell membranes, affecting their structure and fluidity. The degree of FA unsaturation and chain length determine the physicochemical properties of FA, and thus the functionality of cells and tissues as well as lipid mediators produced. Fatty acids can be desaturated endogenously up to the $\Delta 9$ position due to lack of certain enzymes in humans. For this reason LA and ALA must be taken from the diet and are termed essential. Further elongation and desaturation of these fatty acids results in LC PUFA, including EPA, DHA, and AA. However this process is not very efficient in humans and, thus, these FA may be termed conditionally essential. Dietary FA (in the form of TAG) are a major source of energy and determine the fatty acid composition of cell membranes and tissues. The type of fat consumed depends on the dietary sources, typically including saturated fat from animal sources and tropical plant oils (coconut, palm), and polyunsaturated fat from vegetable oils (such as olive oil for MFA; sunflower oil and soybean oil for n-6 PUFA; flaxseed oil for n-3 PUFA) and marine sources (algae and fish oils for LC n-3 PUFA). Saturated FA have been connected to adverse health effects, whereas unsaturated FA are thought to be more beneficial for human health. Specifically MFA and n-3 PUFA are characteristic for their protective role, as opposed to n-6 PUFA, with a special focus on LC n-3 PUFA (EPA, and DHA). In addition, trans FA have been shown to have negative effects on health, whereas conjugated FA (such as CLA) have been shown to have beneficial effects which should be further investigated. Lastly, a major role of fatty acids is being the main constitutional components of lipid classes, including TAG, PL, CE and NEFA. The second part of this review to follow will focus on the role of FA in health and disease, including the current literature on FA physiological roles and practical implications for specific conditions.

\section{ABBREVIATIONS}

AA, Arachidonic acid; AI, Atherogenic index; ALA, $\alpha$-Linolenic acid; CE, Cholesteryl ester/s; CHD, Coronary heart disease; CLA, Conjugated linoleic acid; CN, Carbon number; DHA, Docosahexaenoic acid; DHGLA, Dihomo- $\gamma$-linolenic acid; DG, Diacylglycerol/s; DPA, Docosapentaenoic acid; EFA, Essential fatty acid/s; EPA, Eicosapentaenoic acid; FA, Fatty acid/s; GLA, $\gamma$-Linolenic acid; HDL, High density lipoprotein; IP ${ }_{3}$. Inositoltriphosphate; LA, Linoleic acid; LCAT, Lecithin:cholesterol acyltransferase; LCFA, Long chain fatty acid/s; LDL, Low density lipoprotein; LPC, Lysophosphatidylcholine/ Lysolecithin; LPE, Lysophosphatidylethanolamine; MCFA, Medium chain fatty acid/s; MCT, Medium chain triacyglycerol/s; MFA, Monounsaturated fatty acid/s; MG, Monoacylglycerol/s; NEFA, Non-esterified fatty acid/s; PC, Phosphatidylcholine; PE, Phosphatidylethanolamine; PI, Phosphatidylinositol; PL, Phospholipid/s; PPAR, Peroxisome proliferator-activated receptor/s; PS, Phosphatidylserine; PUFA, Polyunsaturated fatty acid/s; REE, Resting energy expenditure; RONS, Reactive oxygen and nitrogen species; SCFA, Short chain fatty acid/s; SFA, Saturated fatty acid/s; SM, Sphingomyelin; SREBP, Sterol response element binding protein; TAG, Triacylglycerol/s; TEI, Total energy intake; TI, Thrombogenic index; UCP, Uncoupling protein; VLCFA, Very long chain fatty acid/s; VLDL, Very low density lipoprotein.

\section{ACKNOWLEDGEMENT}

Supported by the research projects of the Ministry of Education, Youth and Sport MSM 0021620820 and MSM 0021620807.

\section{REFERENCES}

1. Austin GL, Ogden LG, Hill JO. Trends in carbohydrate, fat, and protein intakes and association with energy intake in normalweight, overweight, and obese individuals: 1971-2006. Am J Clin Nutr 2011; 93(4):836-43. doi: 10.3945/ajcn.110.000141.

2. Sheehy T, Sharma S. The nutrition transition in Barbados: trends in macronutrient supply from 1961 to 2003 . B J Nutr 2010;104:12229.

3. Simopoulos AP. Evolutionary aspects of omega-3 fatty acids in the food supply. Prostaglandins Leukot Essent Fatty Acids 1999;60:421-9.

4. Nelson DL, Cox MM. Lipid Biosynthesis. In: Principles of Biochemistry. New York: W.H. Freeman and Company; 2005. p. 787-815. 
5. SACN (Scientific Advisory Committee on Nutrition) Committee on Toxicity. Advice on fish consumption: benefits and risks. London: The Stationary Office; 2004.

6. EFSA Panel on Dietetic Products, Nutrition and Allergens (NDA). Scientific Opinion on Dietary Reference Values for fats, including saturated fatty acids, polyunsaturated fatty acids, monounsaturated fatty acids, trans fatty acids, and cholesterol. EFSA Journal 2010;8:1461.

7. IUPAC-IUB Commission on Biochemical Nomenclature (CBN). The nomenclature of lipids. Recommendations, 1976. Eur J Biochem 1977;79:11-21.

8. O'Neil MJ, Heckelman PE, Koch CB, Roman KJ, editors. The Merck Index.14th ed. An encyclopedia of chemicals, drugs, and biologicals. USA, NJ: Merck Research Laboratories, Merck \& Co. Inc., Whitehouse Station; 2006.

9. Gunstone FD. Fatty Acid Structure. In: The Lipid Handbook. London: Chapman and Hall; 1994. p. 1-19.

10. Larsson K, Quinn PJ. Physical Properties: Structural and Physical Characteristics. In: The Lipid Handbook. London: Chapman and Hall; 1994. p. 401-65.

11. De Jong WH, Borm PJ. Drug delivery and nanoparticles:applications and hazards. Int J Nanomedicine 2008;3:133-49.

12. Nelson DL, Cox MM. Biological Membranes and Transport. In: Principles of Biochemistry. New York: W.H. Freeman and Company; 2005. p. 369-420.

13. Mead JF. The metabolism of the essential fatty acids. Am J Clin Nutr 1958;6:656-61.

14. Mead JF. The metabolism of polyunsaturated fatty acids. In: Holman RT, editor. Progress in the Chemistry of Fats and other Lipids. Oxford: Pergamon Press; 1971. p. 161-89.

15. Asp ML, Collene AL, Norris LE, Cole RM, Stout MB, Tang SY, Hsu JC, Belury MA. Time-dependent effects of safflower oil to improve glycemia, inflammation and blood lipids in obese, postmenopausal women with type 2 diabetes: A randomized, doublemasked, crossover study. Journal Clin Nutr 2011; Epub ahead of print: doi: 10.1016/j.clnu.2011.01.001.

16. Teng KT, Nagapan G, Cheng HM, Nesaretnam K. Palm Olein and Olive Oil Cause a Higher Increase in Postprandial Lipemia Compared with Lard but Had No Effect on Plasma Glucose, Insulin and Adipocytokines. Lipids 2011. Epub ahead of print: doi 10.1007/s 11745-010-3516-y.

17. Compher C, Setto RW, Lew JI, Rombeau JL. Dietary fibre and its Clinical Applications to Enteral Nutrition. In: Rombeau JL, Rolandelli RH, editors. Clinical Nutrition: Enteral and Tube Feeding. Philadelphia: WB Saunders; 1997. p. 81-95.

18. Hainer V, Kunesova M, Stich V, Zak A, Parizkova J. The role of oils containing triacylglycerols and medium-chain fatty acids in the dietary treatment of obesity. The effect on resting energy expenditure and serum lipids. Cas Lek Cesk 1994;133:373-5.

19. Akihisa T, Kojima N, Katoh N, Ichimura Y, Suzuji H, Fukatsu M, Maranz S, Masters ET. Triterpene alcohol and fatty acid composition of shea nuts from seven African countries. J Oleo Sci 2010;59:351-60.

20. Di Vincenzo D, Maranz S, Serraiocco A, Vito R, Wiesman Z, Bianchi G. Regional variation in shea butter lipid and triterpene composition in four African countries. J Agric Food Chem 2005;53:7473-9.

21. Larsson K, Quinn PJ. Occurrence and Characteristics of Oils and Fats. In: The Lipid Handbook. London: Chapman and Hall; 1994. p. $47-223$.

22. USDA (U.S. Department of Agriculture) Agricultural Research Service. USDA National Nutrient Database for Standard Reference, Release 23. Nutrient Data Laboratory. 2010. Available from: http://www.ars.usda.gov/ba/bhnrc/ndl

23. Astrup A, Dyerberg J, Elwood P, Hermansen K, Hu FB, Jakobsen MU, Kok FJ, Krauss RM, Lecerf JM, Legrand P, Nestel P, Riserus U, Sanders T, Sinclair A, Tender S, Tholstrup T, Willett W. The role of reducing intakes of saturated fat in the prevention of cardiovascular disease: where does the evidence stand in 2010? Am J Clin Nutr 2011; Epub ahead of print: doi: 10.3945/ajen.110.004622.
24. Tholstrup T, Samman S. Postprandial lipoprotein(a) is affected differently by specific individual dietary fatty acids in healthy young men. J Nutr 2004;134:2550-5.

25. Bysted A, Holmer G, Lund P, Sandstrom B, Tholstrup T. Effect of dietary fatty acids on the postprandial fatty acid composition of triacylglycerol-rich lipoproteins in healthy male subjects. Eur J Clin Nutr 2005;59:24-34.

26. Tholstrup T, Vessby B, Sandstrom B. Difference in effect of myristic and stearic acid on plasma HDL cholesterol within $24 \mathrm{~h}$ in young men. Eur J Clin Nutr 2003;57:735-42.

27. Tholstrup T, Marckmann P, Jespersen J, Vessby B, Jart A, Sandstrom B. Effect on blood lipids, coagulation, and fibrinolysis of a fat high in myristic acid and a fat high in palmitic acid. Am J Clin Nutr 1994;60:919-25.

28. Tholstrup T, Marckmann P, Jespersen J, Sandstrom B. Fat high in stearic acid favorably affects blood lipids and factor VII coagulant activity in comparison with fats high in palmitic acid or high in myristic and lauric acids. Am J Clin Nutr 1994;59:371-7.

29. Sanders TA, Oakley FR, Cooper JA, Miller GJ. Influence of a stearic acid-rich structured triacylglycerol on postprandial lipemia, factor VII concentrations, and fibrinolytic activity in healthy subjects. Am J Clin Nutr 2001;73:715-21.

30. Tholstrup T, Teng KT, Raff M. Dietary Cocoa Butter or Refined Olive Oil Does Not Alter Postprandial hsCRP and IL-6 Concentrations in Healthy Women. Lipids 2011; Epub ahead of print: doi: 10.1007/s11745-011-3526-4.

31. Tholstrup T. Influence of stearic acid on hemostatic risk factors in humans. Lipids 2005;40:1229-35.

32. Vemuri M, Kelley DS. The Effects of Dietary Fatty Acids on Lipid Metabolism. In: Chow KC, editor. Fatty Acids in Foods and their Health Implications. Boca Raton: CRC Press; 2007. p. 591-630.

33. Ulbricht TLV, Southgate DAT. Coronary heart disease: seven dietary factors. Lancet 1991;338:985-92.

34. Gotto AM. Contemporary diagnosis and management of lipid disorders. Newtown, PA: Handbooks in Health Care Company, 2004.

35. Raff M, Tholstrup T, Sejrsen K, Straarup EM, Wiinberg N. Diets rich in conjugated linoleic acid and vaccenic acid have no effect on blood pressure and isobaric arterial elasticity in healthy young men. J Nutr 2006;136:992-7.

36. Heggtveit HA, Nera EA, Beare-Rogers JL. Cardiotoxic effects of rapeseed oil: histological and biochemical studies. Recent Adv Stud Cardiac Struct Metab 1973;2:449-54.

37. Beare-Rogers JL, Nera EA. Cardiac fatty acids and histopathology of rats, pigs, monkeys and gerbils fed rapeseed oil. Comp Biochem Physiol B 1972;41:793-800.

38. Beare-Rogers JL, Gordon E. Myocardial lipids and nucleotides of rats fed olive oil or rapeseed oil. Lipids 1976;11:287-90.

39. Stockler S, Opper C, Greinacher A, Hunneman DH, Korejme GC, Unkrig CJ, Hanefeld F. Decreased platelet membrane anisotropy in patients with adrenoleukodystrophy treated with erucic acid (22:1)rich triglycerides. J Inherit Metab Dis 1997;20:54-8.

40. Beare-Rogers JL, Nera EA, Heggtveit HA. Myocardial alteration in rats fed rapeseed oils continaing high or low levels of erucic acid. Nutr Metab 1974;17:213-22.

41. Riccardi G, Giacco R, Rivellese AA. Dietary fat, insulin sensitivity and the metabolic syndrome. Clin Nutr 2004;23:447-56.

42. Costa I, Moral R, Solanas M, Andreu FJ, Ruiz de Villa MC, Escrich E. High corn oil and extra virgin olive oil diets and experimental mammary carcinogenesis: clinicopathological and immunohistochemical p21Ha-Ras expression study. Virchows Arch 2011;458:141-51.

43. Rodrigues HG, Vinolo MA, Magdalon J, Fujiwara H, Cavalcanti DM, Farsky SH, Calder PC, Hatanaka E, Curi R. Dietary free oleic and linoleic acid enhances neutrophil function and modulates the inflammatory response in rats. Lipids 2010;45:809-19.

44. Dyerberg J, Eskesen DC, Andersen PW, Astrup A, Buemann B, Christensen JH, Clausen P, Rasmussen BF, Schmidt EB, Tholstrup T, Toft E, Toubro S, Tender S. Effects of trans- and n-3 unsaturated fatty acids on cardiovascular risk markers in healthy males. An 8 weeks dietary intervention study. Eur J Clin Nutr 2004;58:1062-70. 
45. Osso FS, Moreira AS, Teixeira MT, Pereira RO, Tavares do Carmo MG, Moura AS. Trans fatty acids in maternal milk lead to cardiac insulin resistance in adult offspring. Nutrition 2008;24:727-32.

46. Booker CS, Mann JI. Trans fatty acids and cardiovascular health translation of the evidence base. Nutr Metab Cardiovasc Dis 2008;18:448-56.

47. Salisbury AC, Chan PS, Gosch KL, Buchanan DM, Spertus JA. Patterns and predictors of fast food consumption after acute myocardial infarction. Am J Cardiol 2011; Epub ahead of print: doi: 10.1016/j.amjcard.2010.12.005.

48. Kaasgaard SG, Holmer G, Hoy CE, Behrens WA, Beare-Rogers JL. Effects of dietary linseed oil and marine oil on lipid peroxidation in monkey liver in vivo and in vitro. Lipids 1992;27:740-5.

49. Simopoulos AP. Genetic variants in the metabolism of omega- 6 and omega-3 fatty acids: their role in the determination of nutritional requirements and chronic disease risk. Exp Biol Med 2010;235:78595.

50. Burdge GC. Polyunsaturated fatty acid intakes and alpha-linolenic acid metabolism. Am J Clin Nutr 2010; Epub ahead of print: doi 10.3945/ajen.110.008169.

51. Simopoulos AP, Leaf A, Salem NJr. Essentiality of and recommended dietary intakes for omega- 6 and omega-3 fatty acids. Ann Nutr Metab 1999;43:127-30.

52. Brenna JT. Efficiency of conversion of alpha-linolenic acid to long chain n-3 fatty acids in man. Curr Opin Clin Nutr Metab Care 2002;5:127-32.

53. Brenna JT, Salem NJr., Sinclair AJ, Cunnane SC. alpha-Linolenic acid supplementation and conversion to n-3 long-chain polyunsaturated fatty acids in humans. Prostaglandins Leukot Essent Fatty Acids 2009;80:85-91.

54. Simopoulos AP. Omega-6/omega-3 essential fatty acids: biological effects. World Rev Nutr Diet 2009;99:1-16.

55. Simopoulos AP. Omega-3 fatty acids in health and disease and in growth and development. Am J Clin Nutr 1991;54:438-63.

56. Burdge GC, Powell J, Dadd T, Talbot D, Civil J, Calder PC. Acute consumption of fish oil improves postprandial VLDL profiles in healthy men aged 50-65 years. Br J Nutr 2009;102:160-5.

57. Calder PC, Yaqoob P. Omega-3 polyunsaturated fatty acids and human health outcomes. Biofactors 2009;35:266-72.

58. Calder PC, Yaqoob P. Omega-3 (n-3) fatty acids, cardiovascular disease and stability of atherosclerotic plaques. Cell Mol Biol 2010;56:28-37.

59. Rossmeisl M, Syrovy I, Baumruk F, Flachs P, Janovska P, Kopecky J. Decreased fatty acid synthesis due to mitochondrial uncoupling in adipose tissue. FASEB J 2000;14:1793-1800.

60. Flachs P, Horakova O, Brauner P Rossmeisl M, Pecina P, Franssenvan Hal N, Ruzickova J, Spojarova J, Drahota Z, Vlcek C, Keijer J, Houstek J, Kopecky J. Polyunsaturated fatty acids of marine origin upregulate mitochondrial biogenesis and induce beta-oxidation in white fat. Diabetologia 2005;48:2365-75.

61. Janovska P, Kopecky J. Adipose tissue-muscle interactions and the metabolic effects of n-3 LCPUFA - implications for programming effects of early diet. Adv Exp Med Biol 2009;646:149-57.

62. Burdge G. Alpha-linolenic acid metabolism in men and women: nutritional and biological implications. Curr Opin Clin Nutr Metab Care 2004; 7:137-44.

63. Calder PC. The relationship between the fatty acid composition of immune cells and their function. Prostaglandins Leukot Essent Fatty Acids 2008;79:101-8.

64. Calder PC. N-3 polyunsaturated fatty acids and inflammation: from molecular biology to the clinic. Lipids 2003;38:343-52.

65. Damsgaard CT, Lauritzen L, Calder PC, Kjaer TR, Frokiaer H. Reduced ex vivo interleukin-6 production by dietary fish oil is not modified by linoleic acid intake in healthy men. J Nutr 2009;139:1410-4.
66. Calder PC, Deckelbaum RJ. Harmful, harmless or helpful? The n-6 fatty acid debate goes on. Curr Opin Clin Nutr Metab Care 2011:14:113-4.

67. Schoonjans K, Martin G, Staels B, Auwerx J. Peroxisome proliferator-activated receptors, orphans with ligands and functions. Curr Opin Lipidol 1997;8:159-66.

68. Staels B. The PPAR System and Regulation of Lipoprotein Metabolism. In: Betteridge DJ, editor. Lipids and vascular disease. London: Martin Dunitz Publ; 2000. p. 27-37.

69. Vergroesen AJ. Essential Fatty Acids, Biomembranes and Eicosanoid Metabolism. In: Vergroesen AJ, Crawford M, editors. The role of fats in human nutrition. London: Academic Press; 1989. p. 17-29.

70. Lawson RE, Moss AR, Givens DI. The role of dairy products in supplying conjugated linoleic acid to man's diet: a review. Nutr Res Rev 2001;14:153-72.

71. Raff M, Tholstrup T, Basu S, Nonboe P, Sorensen MT, Straarup EM. A diet rich in conjugated linoleic acid and butter increases lipid peroxidation but does not affect atherosclerotic, inflammatory, or diabetic risk markers in healthy young men. J Nutr 2008;138:509-14

72. Raff M, Tholstrup T, Toubro S, Bruun JM, Lund P, Straarup EM, Christensen R, Sandberg MB, Mandrup S. Conjugated linoleic acids reduce body fat in healthy postmenopausal women. J Nutr 2009;139:1347-52.

73. Pariza MW, Hargraves WA. A beef-derived mutagenesis modulator inhibits initiation of mouse epidermal tumors by 7,12-dimethylbenz[a]anthracene. Carcinogenesis 1985;6:591-3.

74. Pariza MW, Hargraves WA, Boissonneault GA. Modulation of carcinogenesis by a beef-derived mutagenesis modulator, and by dietary fat. Prog Clin Biol Res 1986; 206:265-71.

75. Tholstrup T, Raff M, Straarup EM, Lund P, Basu S, Bruun JM. An oil mixture with trans-10, cis-12 conjugated linoleic acid increases markers of inflammation and in vivo lipid peroxidation compared with cis-9, trans-11 conjugated linoleic acid in postmenopausal women. J Nutr 2008;138:1445-51.

76. Pineda-Torra, I, Gervois P, Staels B. Peroxisome proliferator-activated receptor alpha in metabolic disease, inflammation, atherosclerosis and aging. Curr Opin Lipidol 1999;10:151-9.

77. Tvrzicka E, Vecka M, Zak A. Conjugated linoleic acid-the dietary supplement in the prevention of cardiovascular diseases. Cas Lek Cesk 2007;146:459-65.

78. Harwood JL. Lipid Structure. In: The Lipid Handbook. London: Chapman and Hall; 1994. p. 21-46.

79. Havel RJ, Eder HA, Bragdon JH. The distribution and chemical composition of ultracentrifugally separated lipoproteins in human serum. J Clin Invest 1955;34:1345-53.

80. Zuijdgeest-van Leeuwen SD, van der Heijden MS, Rietveld T, van den Berg JW, Tilanus HW, Burgers JA, Wilson JH. Fatty acid composition of plasma lipids in patients with pancreatic, lung and oesophageal cancer in comparison with healthy subjects. Clin Nutr 2002;21:225-30.

81. Tvrzicka E, Vecka M, Stankova B, Zak A. Analysis of fatty acids in plasma lipoproteins by gas chromatography-flame ionization detection: Quantitative aspects. Analytica Chimica Acta 2002;465:33750 .

82. Zak A, Vecka M, Tvrzicka E, Jachymova M, Dusejovska M, Janikova L, Stankova B, Vavrova L, Kodydkova J, Zeman M. Composition of the esterified fatty acids and lipid peroxidation in metabolic syndrome. Cas Lek Cesk 2007;146:484-91.

83. de Almeida IT, Cortez-Pinto H, Fidalgo G, Rodrigues D, Camilo ME. Plasma total and free fatty acids composition in human nonalcoholic steatohepatitis. Clin Nutr 2002;21:219-23. 